\title{
Genetic parameters of testicular measurements in Merino rams and the influence of scrotal circumference on total flock fertility
}

\author{
G. Dugumaa ${ }^{1 *}$, S.W.P. Cloete ${ }^{2}$, S. J. Schoeman ${ }^{1,}$ and G.F. Jordaan ${ }^{1}$ \\ ${ }^{1}$ Department of Animal Sciences, University of Stellenbosch, P. Bag X1, Matieland 7602, South Africa \\ ${ }^{2}$ Elsenburg Agricultural Research Centre, P. Bag X1, Elsenburg 7607, South Africa
}

\begin{abstract}
Genetic parameter estimates for scrotal circumference (SC), testis diameter (TD) and two-tooth liveweight (LW) were obtained for 1380 two-tooth Merino rams born from 1986 to 1998 on the Tygerhoek Experimental Farm. The effect of SC of service sires $(n=263)$ on ewe fertility was also investigated. Year of birth, selection group and LW were significant sources of variation for both SC and TD. SC had a significant effect on ewe fertility. Heritability estimates ranged from 0.29 to $0.40,0.25$ to 0.38 and from 0.49 to 0.52 for SC, TD and LW, respectively. Adjustment for LW decreased heritability estimates of SC and TD and the genetic correlations between the latter traits. Rams with an unadjusted SC of less than $30 \mathrm{~cm}$ should not be used.
\end{abstract}

Keywords: Flock reproductivity, genetic correlations, heritability, Merino sheep, testicular measurements

${ }^{\#}$ Corresponding author. E-mail address: sjsc@sun.ac.za

*Present address: Bako Agricultural Research Centre, P.O. Box 3, West Shoa, Bako, Ethiopia.

\section{Introduction}

Fertility of males and females and successful reproduction are important to efficient livestock production (Meyer et al., 1991). However, most female reproductive traits are lowly heritable and selection intensities for them are usually low; thus, little improvement through selection is expected (Smith et al., 1989).

In contrast to low heritabilities for female reproductive traits, moderate heritabilities have been summarised for testicular traits in sheep (Fogarty, 1995). Particularly, since Land (1973) suggested a likely genetic correlation between reproductive characters of males and females, considerable research has been directed at studying testicular traits. Several authors indicated that males with larger testes have either greater sperm production or higher daily sperm output (Cameron et al., 1984; Purvis et al., 1984; MukasaMugerwa \& Ezaz, 1992). In order to increase flock fertility, improve the genetic merit of a flock and to reduce the number of breeding males, rams with superior reproductive traits are required (Mukasa-Mugerwa \& Ezaz, 1992). Venter et al. (1984) also proposed that minimum scrotal circumference standards at a certain age should be established for individual breeds. In addition, the value of testicular size as an indirect selection criterion for the improvement of female reproduction is dependent on the heritability of testicular size and the genetic correlation between testicular size and female reproductive traits (Matos et al., 1992). Therefore, the objectives of this study were to investigate genetic and non-genetic factors affecting testis measurements and to examine the effect of testis size on fertility in the flock of Merinos maintained at the Tygerhoek Experimental Farm.

\section{Materials and Methods}

Records of testis measurements of rams at the Tygerhoek Experimental Farm covering the period 1986 through 1998 were used in this study. After editing, 1380 records on two-tooth rams were available where scrotal circumference (SC), testis diameter (TD) as well as liveweight (LW) were recorded. After running a preliminary analysis, those records deviating more than three standard deviations from the respective means were excluded from the model of analyses. Measurements were taken at about 16 months of age (when $\pm 80 \%$ of mature liveweight for this flock is attained) before using selected male rams for handmating. In this flock, it was approximately two months before age at first breeding at 18 months of age.

Scrotal circumference was measured as described in the literature (Schoeman \& Combrink, 1987; Mukasa-Mugerwa \& Ezaz, 1992; Gojjam et al., 1995; Gizaw \& Thwaites, 1997). The testes were brought firmly and evenly to the bottom of the scrotum until ventral skin folds were eliminated. The testes were then held firmly in place by grasping the neck of the scrotum with one hand above the heads of the epididymes. The opposite hand then guided a flexible tape upward from the bottom of the scrotum. The area of the 
scrotum with the greatest circumference was then identified for measurement. Manual pressure on the tape was exerted to the extent of slight skin indentation. Testis diameter measurements were taken with a caliper at the anterior-posterior position on each testis at its maximum width as described by Schoeman \& Combrink (1987). The total of both right and left testis diameters was taken as the testis diameter for individual animals.

The General Linear Models of the Statistical Analysis System (SAS, 1996) were used in the analyses of the data to determine the importance of various fixed effects on testis measurements and LW. The final models of analysis for SC and TD included birth year of lambs (1986 to 1998) and group (group of animals selected for an increased clean fleece weight and control) as fixed effects and LW as a linear covariable. In the case of LW, birth year and group were fitted as fixed effects. Preliminary models for testis measurements and LW also included age of dam, birth type and all possible two-factor interactions among fixed effects. None of these were found to be significant sources of variation and they were not included in the final models.

In the case of ewe fertility, a total of 3717 ewe records (from 1988 to 1999) was used. In this analysis ewes that lambed were recorded as ' 1 ' and those that did not, were recorded as ' 0 '. Data were analysed using the CATMOD procedure of SAS (1996). Subclass proportions were computed using the procedure of Rege \& Sherington (1996) as implemented by Rege (1997).

The fixed effects fitted for ewe fertility were ewe age at lambing (2- to 6-yr-old) and SC of 263 service sires which was grouped into three categories $(1=24$ to $30 \mathrm{~cm} ; 2=31$ to $35 \mathrm{~cm} ; 3=36$ to $40 \mathrm{~cm})$. The high positive genetic correlation between SC and TD, the relatively larger $\mathrm{h}^{2}$ estimates for SC than for TD (Toe et al., 2000) and ease of measurement for SC as compared to TD resulted in the use of models that contained only SC for the analysis of these data.

Variance components for testis measurements were estimated with Restricted Maximum Likelihood (REML) procedures, using the VCE 4.2.5 package developed by Groeneveld (1998). An animal model was fitted which included a random direct animal effect and the fixed effects used in GLM analyses. The genetic correlations between traits were estimated using two-trait pairwise analyses.

The model fitted for both unitrait and two-trait analyses was as follows:

where:

$$
\mathrm{Y}=\mathrm{Xb}+\mathrm{Z} \mathbf{a}+\mathbf{e}
$$

$\mathrm{y}=$ vector of records

$\mathbf{b}=$ vector of fixed effects which included year of birth of rams and selection group

$\mathbf{a}=$ vector of random animal effects (direct genetic)

$\mathrm{X}=$ incidence matrix for fixed effects

$\mathrm{Z}=$ incidence matrix for random effects, and

$\mathbf{e}=$ vector of random residual effects.

It was assumed that all effects in the models are independent and normally distributed.

\section{Results}

The means, coefficients of variation and significance levels of the fixed effects for SC, TD and LW are presented in Table 1. Both SC $\left(y=20.86+0.221 X ; r^{2}=0.30\right)$ and TD $\left(y=74.97+0.782 X ; r^{2}=0.20\right)$ were related to LW while SC, TD and LW, were effected by year of birth $(\mathrm{P}<0.001)$ and selection group (P $<0.05)$. The line that was selected for increased clean fleece weight had larger SC and TD measurements than rams from the control group. They were also on average $5.0 \mathrm{~kg}$ heavier than control group contemporaries.

The maximum likelihood analysis of variance for ewe fertility is presented in Table 2 with the predicted probabilities for the three SC categories in Table 3. Ewe fertility was significantly $(\mathrm{P}<0.001)$ influenced by ewe age and by the SC of the service sire. It increased with an increase in ewe age from two to six years. The average ewe fertility was 0.93 , and it varied from 0.90 at two years of age to between 0.93 and 0.95 at later ages. Mean ewe fertility increased from 0.88 in SC category 1 to 0.96 and 0.95 in SC categories 2 and 3, respectively (Table 3). 
Table 1 Means, coefficients of variation (CV) and significance levels of fixed effects and the covariate (LW for SC and TD) for scrotal circumference (SC), testis diameter (TD) and liveweight (LW) of 16 month old Merino rams

\begin{tabular}{llll}
\hline & \multicolumn{3}{c}{ Traits } \\
\cline { 2 - 4 } & $\mathrm{SC}(\mathrm{cm})$ & $\mathrm{TD}(\mathrm{mm})$ & $\mathrm{LW}(\mathrm{kg})$ \\
\hline Mean & 32.1 & 112.2 & 53.8 \\
$\mathrm{CV}(\%)$ & 7.2 & 8.9 & 11.9 \\
& & & $* * *$ \\
Year of birth & $* * *$ & $* * *$ & $* * *$ \\
Selection group & $* * *$ & $*$ & - \\
Liveweight $(\mathrm{LW})$ & $* * *$ & $* * *$ & 34.1 \\
$\mathrm{R}^{2}$ model $(\%)$ & 48.9 & 43.1 &
\end{tabular}

Table 2 Maximum likelihood analysis of variance of ewe fertility

\begin{tabular}{lcc}
\hline Source & $\begin{array}{c}\text { Degrees of } \\
\text { Freedom }\end{array}$ & Chi-square \\
\hline Intercept & 1 & $1325.93^{* * *}$ \\
Ewe age & 4 & $20.78^{* * *}$ \\
Scrotal Circumference & 2 & $61.80^{* * *}$ \\
Likelihood ratio & 8 & $21.95 * * *$ \\
\hline$* * * \mathrm{P}<0.001$ & &
\end{tabular}

Table 3 Predicted probabilities of ewe fertility for scrotal circumference (SC)

\begin{tabular}{lcc}
\hline Effect & Category & Predicted estimates $( \pm$ s.e. $)$ \\
\hline Overall & & $0.93 \pm 0.004$ \\
SC & 1 & $0.88 \pm 0.010$ \\
& 2 & $0.96 \pm 0.004$ \\
& 3 & $0.95 \pm 0.008$ \\
\hline
\end{tabular}

Estimates of heritability $\left(\mathrm{h}^{2}\right)$ for SC, TD and LW from the unitrait analyses are presented in Table 4, while those of two-trait pairwise (SC or TD correlated with $\mathrm{LW}$ ) analyses are presented in Table 5. Heritability estimates for testicular measurements (both from unitrait and two-trait analyses) ranged from medium to high. The estimates of $\mathrm{h}^{2}$ were generally higher in the two-trait pairwise analyses for testis measurements (Table 5). Adjustments for LW reduced the $\mathrm{h}^{2}$ estimates for both testis traits. Estimates of genetic correlations between SC and TD investigated were unity, indicating that they could be considered as the same trait for all practical purposes.

Table 4 Estimated variance components and genetic parameters for scrotal circumference (SC), testis diameter (TD) and liveweight (LW) from unitrait analysis

\begin{tabular}{lccc}
\hline Variance components & SC & TD & LW \\
\hline$\sigma^{2}{ }_{a}$ & 1.586 & 108.885 & 21.536 \\
$\sigma^{2}{ }_{e}$ & 3.838 & 164.299 & 20.208 \\
$\sigma_{p}^{2}$ & 5.424 & 273.184 & 41.744 \\
Heritability $\left(\mathrm{h}^{2}\right) \pm$ s.e. & $0.29 \pm 0.04$ & $0.25 \pm 0.05$ & $0.52 \pm 0.05$ \\
\hline
\end{tabular}

\section{Discussion}

The relationship between LW and testis measurements was in general agreement with that reported in the literature (Schoeman \& Combrink, 1987; Mukassa-Mugerwa \& Ezaz, 1992; Gojjam et al., 1995). The 
testis size differences between the selected and control groups may reflect the LW differences between the two groups. Heydenrych et al. (1984) indicated that selection for clean fleece weight in this flock has resulted in a correlated increase in LW. Comparable results were reported also in the studies by Cloete et al. $(1992 ; 1998)$, which were possibly closer to the period over which data for the present study were derived.

Table 5 Heritability estimates on diagonal (in bold letters) and genetic correlations ( \pm s.e.) between scrotal circumference (SC) and testis diameter (TD), SC and liveweight (LW) and TD and LW, either adjusted or unadjusted for LW differences

\begin{tabular}{lccccc}
\hline & \multicolumn{3}{c}{ Unadjusted for LW } & \multicolumn{2}{c}{ Adjusted for LW } \\
\cline { 2 - 6 } Trait & SC & TD & LW & SC & TD \\
\hline SC & $\mathbf{0 . 4 0} \pm \mathbf{0 . 0 5}$ & $1.00 \pm 0.06$ & $0.70 \pm 0.05$ & $\mathbf{0 . 2 9} \pm \mathbf{0 . 0 5}$ & $1.00 \pm 0.08$ \\
TD & & $\mathbf{0 . 3 8} \pm \mathbf{0 . 0 3}$ & $0.68 \pm 0.06$ & & $\mathbf{0 . 3 0} \pm \mathbf{0 . 0 3}$ \\
LW & & & $\mathbf{0 . 5 2} \pm \mathbf{0 . 0 5}$ & & \\
\hline
\end{tabular}

The effect of year on SC, TD and LW may be a reflection of differences in feed availability between years, caused by differences in rainfall. The Southern Cape area is subjected to dry years with limited feed availability. Purvis (1985) reported that environmental influences had a significant influence on variation in gonadal size at all ages up to 19 months. Testicular size was drastically reduced in grazing rams (Master \& Fels, 1984) and rams either gain or lose testicular size at a greater rate than LW (Oldham et al., 1978; Master \& Fels, 1984).

The significant effect of SC on ewe fertility found, was in contrast to results reported by Gizaw \& Thwaites (1997). It, however, confirmed an earlier suggestion by Schoeman \& Combrink (1987) that testicular size serves as an indicator of ram fertility and that testis size was positively related to ewe fertility under heavy breeding pressure. It was also suggested that testis size measured at puberty was a more accurate indication of ovulation rate in female relatives than either prepubertal or postpubertal size (Schoeman et al., 1987).

The $\mathrm{h}^{2}$ estimates for testis traits ranged from medium to high and were in general agreement with most of the literature estimates (Fogarty, 1995; Burfening \& Davis, 1998). In his review, Fogarty (1995) summarised $\mathrm{h}^{2}$ estimates for $\mathrm{SC}$, which ranged from 0.08 to 0.50 with a mean value of 0.23 . Corresponding estimates for TD ranged between 0.10 and 0.69 with a mean value of 0.37 . The present $\mathrm{h}^{2}$ estimates were lower than those reported by Fossceco \& Notter (1995) and Toe et al. (2000), but larger than estimates reported by Al-Shorepy \& Notter (1996).

The $\mathrm{h}^{2}$ estimates for testis measurements differed between the unitrait and two-trait pairwise analyses and tended to be larger in the two-trait analyses. Lin \& Lee (1986) also indicated that parameter estimates vary depending on the type of analysis (single- or multitrait model) with those from multitrait analyses being more accurate than those from unitrait analyses.

Adjustments for LW differences reduced $\mathrm{h}^{2}$ estimates, as was also found by Fogarty et al. (1980) and by Toe et al. (2000). Fogarty et al. (1980) reported that after correcting for LW, the $\mathrm{h}^{2}$ estimates of SC and TD were reduced by 41 and $24 \%$, respectively. On the other hand, apparent increases in $\mathrm{h}^{2}$ estimates of testicular measurements following adjustment for LW were also reported (Matos \& Thomas, 1992). They reported that $\mathrm{h}^{2}$ for SC in Rambouillet rams was nearly constant between 90 and 180 days, but that linear adjustment for LW over this age range increased $h^{2}$ estimates of SC by $42 \%$. According to Matos et al. (1992), adjustment of testis traits for LW may result in slower genetic progress in female reproductive traits than when selection is based on SC unadjusted for LW.

Genetic correlations between SC and TD were high and in accordance with those reported by Toe et al. (2000) for yearling Horro and Menz sheep of Western and Central Ethiopia, respectively. The genetic correlations between both testis traits and LW found in the present study agreed with a 0.62 weighted average for the genetic correlation between LW and testis measurements, as reviewed by Fogarty (1995). Bourdon \& Brinks (1986) suggested that adjustment for live weight was likely to remove differences in SC associated with genetic differences in weight. Literature results (Haley et al., 1990; Lee et al., 1991; Burfening \& Davis, 1998) indicated that selection of rams based on testis size adjusted for LW would result in a faster increase in number of lambs born but a decrease in mature liveweight, owing to an antagonism 
between lamb production and live weight. In this flock, estimates of heritability ranging from 0.32 to 0.55 were reported for two-tooth liveweight (Cloete et al., 1998; Snyman et al., 1998). Thus, their offspring would have a lighter LW if selection would be based on testis size adjusted for LW. This decrease in LW might not be desirable in Merino sheep owing to its small size and where approximately 50 to $60 \%$ of their income is generated through mutton production (Snyman et al., 1998) and the well documented positive genetic correlations between LW and wool production (Heydenrych, 1975; Heydenrych et al., 1984; Cloete et al., 1998).

\section{Conclusions}

Estimates of $\mathrm{h}^{2}$ for $\mathrm{SC}$ and TD, both from the unitrait and two-trait pairwise analyses, were moderate to high. Genetic progress thus seems likely if it is seen as a breeding objective. Moreover, the high and positive genetic correlations between testis traits and LW could indicate that selection for larger testis size will also improve flock reproductivity via the well-established association of LW with reproduction rate (Fogarty, 1995). In this study, rams with larger SC induced a significantly higher fertility and general productivity in their ewe mates. Owing to the major contribution of the Merino industry in lamb production, it is recommended that rams with an unadjusted SC of less than $30 \mathrm{~cm}$ should be culled. The use of rams with larger testis measurements will furthermore allow a reduction in the number of rams required for breeding each year and increase the overall reproductive efficiency of the current flock. Reanalysis of the data, including other reproductive traits and the estimation of genetic correlations between $\mathrm{SC}$ and female traits when sufficient data have been recorded, are suggested.

\section{References}

Al-Shorepy, S.A. \& Notter, D.R., 1996. Genetic variation and covariation for ewe reproduction, lamb growth and lamb scrotal circumference in a fall-lambing sheep flock. J. Anim. Sci. 74, 1490-1498.

Bourdon, R.M. \& Brinks, J.S., 1986. Scrotal circumference in yearling Hereford bulls: Adjustment factors, heritabilities and genetic, environmental and phenotypic relationships with growth traits. J. Anim. Sci. 62, 958-967.

Burfening, P.J. \& Davis, K.C., 1998. Genetic parameter estimates for scrotal circumference in ram lambs and estimated co-variances with ewe body weight, fleece traits and reproductive rate. Sheep and Goat Res. J. $14,121-126$.

Cameron, A.W.N., Fairnie, I.J., Curnow, D.H., Keogh, E.J. \& Lindsay, D.R., 1984. The relationship between testicular size and daily sperm output of rams. Proc. Aust. Soc. Anim. Prod. 15, 658.

Cloete, S.W.P., Delport, G.J., Erasmus, G.J., Olivier, J.J., Heydenrych, H.J. \& Du Toit, E., 1992. Environmental and genetic trends in clean fleece mass, live mass and fibre diameter in selection and control flocks involving a selection experiment for increased clean fleece mass in South African Merino sheep. S. Afr. J. Anim. Sci. 22, 50-57.

Cloete, S.W.P., Olivier, J.J., Snyman, M.A. \& Du Toit, E., 1998. Genetic parameters and trends in a selection experiment for increased clean fleece weight involving South African Merinos. Aust. J. Exp. Agric. 38, 427-432.

Fogarty, N.M., 1995. Genetic parameters for live weight, fat and muscle measurements, wool production and reproduction in sheep: a review. Anim. Breed. Abstr. 63, 101-143.

Fogarty, N.M., Lunstra, D.D., Young, L.D. \& Dickerson, G.E., 1980. Breed effects and heritability of testis measurements in sheep. J. Anim. Sci. 51 (Suppl. 1), 117.

Fossceco, S.L. \& Notter, D.R., 1995. Heritabilities and genetic correlations of body weight, testis growth and ewe lamb reproduction traits in crossbred sheep. Anim. Sci. 60, 185-195.

Gizaw, S. \& Thwaites, C.J., 1997. Changes in liveweight, body condition and scrotal circumference and their relationships with sexual activity and flock fertility in Ethiopian Horro rams over a 3-cycle joining period. J. Agric. Sci., Camb. 128, 117-121.

Gojjam, Y., Gizaw, S., Abegaz, S. \& Thwaites, C.J., 1995. Relationships between body weight, and scrotal characteristics and between environmental effects and fertility in Ethiopian Horro rams. J. Agric. Sci., Cambridge. 124, 297-299.

Groeneveld, E., 1998. A multivariate multimodel REML (co)variance component estimation package. User's Guide, Version 4.2.5, D-31535, Neustadt, Germany. 
Haley, C.S., Lee, G.J., Ritchie, M. \& Land, R.B., 1990. Direct responses in males and correlated responses for reproduction in females to selection for testicular size adjusted for body weight in young male lambs. J. Reprod. Fert. 89, 383-396.

Heydenrych, H.J., 1975. 'n Studie van kuddestatistieke, nie-genetiese faktore, genetiese parameters en seleksievordering met betrekking tot die Tygerhoek Merinokudde. Ph.D. (Agric) treatise. University of Stellenbosch. (English summary in Agricultural Research. 1976. Dept. Agric. Tech. Services, Pretoria, South Africa. 1977, 125-127).

Heydenrych, H.J., Du Plessis, J.J. \& Cloete, S.W.P., 1984. Increasing the wool production of Merino sheep in the South Western Districts of South Africa by direct and indirect selection. In: Proc. $2^{\text {nd }}$ Wrld Congr. Sheep and Beef Cattle Breeding. Eds. Hofmeyr, J.H. \& Meyer, E.H.H., Pretoria, South Africa, p.p. 399407.

Land, R. B., 1973. Expression of female sex-limited characters in the male. Nature. 241, 208-209.

Lee, G.J., Haley, C.S. \& Land, R.B., 1991. Correlated changes in growth patterns and overall production efficiency following selection for testis size adjusted for body weight in young male lambs. Anim. Prod. $52,477-488$.

Lin, C.Y. \& Lee, A.J., 1986. Sequential estimation of genetic and phenotypic parameters in multitrait mixed model analysis. J. Dairy Sci. 69, 2696-2703.

Master, D.G. \& Fels, H.E., 1984. Seasonal changes in the testicular size of grazing rams. Proc. Aust. Soc. Anim. Prod. 15, 444-447.

Matos, C.A.P. \& Thomas, D.L., 1992. Physiology and genetics of testicular size in sheep: a review. Livest. Prod. Sci. 32, 1-30.

Matos, C.A.P., Thomas, D.L., Nash, T.C., Waldron, D.F. \& Stookey, J.M., 1992. Genetic analyses of scrotal circumference, size and growth in Rambouillet lambs. J. Anim. Sci. 70, 43-50.

Meyer, K., Hammond, K., Mackinnon, M.J. \& Parnell, P.F., 1991. Estimates of covariances between reproduction and growth in Australian beef cattle. J. Anim. Sci. 69, 3533-3543.

Mukasa-Mugerwa, E. \& Ezaz, Z., 1992. Relationship of testicular growth and size to age, body weight and onset of puberty in Menz ram lambs. Theriogenology. 38, 979-988.

Oldham, C.M., Adams, N.R. Gherardi, P.B., Lindsay, D.R. \& Mackintosh, J.B., 1978. The influence of level of feed intake on sperm-producing capacity of testicular tissue in the ram. Aust. J. Agric. Res. 29, 173179.

Purvis, I.W., 1985. Genetic relationships between male and female reproductive traits. Ph.D. Thesis, University of New England, Armidale, NSW, Australia.

Purvis, I.W., Kilgour, R.J., Edey, T.N. \& Piper, L.R., 1984. Variation in testis diameter and serving capacity within and between 14 Merino lines. Proc. Aust. Soc. Anim. Prod. 15, 545-548.

Rege, J.E.O., 1997. LOGMLVAR: A computer program for estimating variances of predicted probabilities from maximum-likelihood estimates in a logit response function. Int. Livestock Res. Inst. (ILRI), Addis Ababa, Ethiopia.

Rege, J.E.O. \& Sherington, J., 1996. A method for estimating sampling variances of predicted probabilities from maximum-likelihood estimates in a logit response function. Discovery and Innovation 8, 171.

SAS, 1996. Statistical Analysis Systems SAS user's guide. SAS Institute Inc., Cary, North Carolina.

Schoeman, S.J. \& Combrink, G.C., 1987. Testicular development in Dorper, Döhne Merino and crossbred rams. S. Afr. J. Anim. Sci. 17, 22-26.

Schoeman, S.J., Els, H.C. \& Combrink, G.C., 1987. A preliminary investigation into the use of testis size in cross-bred rams as a selection index for ovulation rate in female relatives. S. Afr. J. Anim. Sci. 18, 144147.

Smith, B.A., Brinks, J.S. \& Richardson, G.V., 1989. Relationships of sire scrotal circumference to offspring reproduction and growth. J. Anim. Sci. 67, 2881-2885.

Snyman, M.A., Cloete, S.W.P. \& Olivier, J.J., 1998. Genetic and phenotypic correlations of total weight of lamb weaned with body weight, clean fleece weight and mean fibre diameter in three South African Merino flocks. Livest. Prod. Sci. 55, 157-162.

Toe, F., Rege, J.E.O., Mukasa-Mugerwa, E., Tembely, S., Anindo, D., Baker, R.L. \& Lahlou-Kassi, A., 2000. Reproduction characteristics of Ethiopian highland sheep. I. Genetic parameters of testicular measurements in ram lambs and relationship with age at puberty in ewe lambs. Small Rumin. Res. 36, $227-240$ 
(C) South African Society for Animal Science

Venter, H.A.W., Van Zyl, J.G.E. \& Tami Vasconcellos, O.A.D.R., 1984. Comparative testicular development in young beef bulls. In: Proc. $2^{\text {nd }}$ Wrld Congr. Sheep and Beef Cattle Breeding. Eds. Hofmeyr, J.H. \& Meyer, E.H.H., April 1984, Pretoria, South Africa. 